\title{
Relationship Between Product Performance and Lean Product Development Tool
}

\author{
Mauton Gbededo ${ }^{1,2, ~ *}$, Daniel Aikhuele ${ }^{1}$, Desmond Ighravwe ${ }^{1}$ \\ ${ }^{1}$ Department of Mechanical Engineering, Bells University of Technology, Ota, Ogun-State, Nigeria \\ ${ }^{2}$ Department of Mechatronics Engineering, Federal University, Oye-Ekiti, Ekiti State, Nigeria
}

Email address:

mgbededo@gmail.com (M. Gbededo)

${ }^{*}$ Corresponding author

\section{To cite this article:}

Mauton Gbededo, Daniel Aikhuele, Desmond Ighravwe. Relationship Between Product Performance and Lean Product Development Tool. American Journal of Mechanical and Industrial Engineering. Vol. 5, No. 3, 2020, pp. 31-43. doi: 10.11648/j.ajmie.20200503.11

Received: June 8, 2020; Accepted: June 22, 2020; Published: August 5, 2020

\begin{abstract}
In today's global economy, the introduction of new methods, designs, products and processes have been accelerating in geometric progression due to changing consumers' needs in the face of global competitions and technological advancement in product development. Product development managers and design stakeholders are facing real pressure to continuously adopt new system architecture and operational parameters to remain competitive. The viability of the product development and manufacturing firm now depends largely on how well they are able to respond to these changes in order to meet the customer requirements while becoming lean. The study will also provide a tool for monitoring the relationship between product performance and the Lean Product Development Tool (LPDT). It evaluates the relationship between Maggi spice production, of a Consolidated Foods Limited, in Nigeria and its relationship with DMAIC (Define, Measure, Analyse, Improve and Control) model, a lean six sigma tool, for evaluating root causes of product defects. At the end of the lean implementation, product performance of the pilot line, Omori Line 1 increases from $60 \%$ to $76 \%$ and a cost savings of NGR 12.03 million were realized at the end of the project.
\end{abstract}

Keywords: Product Development, DMAIC Model, Product Defects, Lean Six Sigma Tool

\section{Introduction}

In today's global economy, the introduction of new methods, designs, products and processes have been accelerating in geometric progression due to changing consumers' needs in the face of global competitions and technological advancement in product development. Manufacturing companies and manufacturing stakeholders are facing real pressure to continuously adopt new system architecture and operational parameters to remain competitive [1]. The global market has become extremely competitive and these companies have adopted several lean approaches to achieve minimal defects towards reducing manufacturing cost and optimizing profits. In the past decades, product development tools normally applied in response to these market trends include the Just-in-time (JIT) technique, which is used for reducing the in-process inventory and associated carrying cost. Standardized work, which is a guide on how to perform a task exactly the same way all the time, Kaizen improvement tool, is about the introduction of brief meetings for brainstorming and for the prioritization of improvement opportunities within the Research \& Development (R\&D) cycle during the product development process. Quality Function Deployment (QFD), is for capturing the voice of the customer and to make valuebased decisions about the new product. Others includes; Value Stream Mapping (VSM) for analyzing the current state of the product development process and for designing the future state for the series of events that will take the product(s) from the raw material inception through delivery to the customer with the pull system for ensuring all activities during the design phase are in agreement with the endcustomer requirements [1]. For the purpose of this study, these tools will be regarded as Lean Product Development Tools (LPDT).

The results of evaluation of these LPDT led to increase in production output, lesser lead time but the output is always 
accompanied with large amount of scraps (in form of product defects). The need of zero defect manufacturing has become a necessity in the global market as a result changing consumers' needs and high costs of manufacturing. One of the ways of achieving zero defect manufacturing is implementing a continuous quality improvement model. Of late, manufacturing companies have been adopting Six Sigma as the continuous quality improvement model for achieving zero defect manufacturing [2]. Six Sigma emerged in Motorola in the late 1980s [3]. Six Sigma is a successful tool used by companies to reduce cost, increase profitability, reduce defects, reduce variations in the design and improve satisfaction of the customer.

Six Sigma aims to combine statistical and quality tools into a standard methodology designated by the acronym DMAIC, which is described as define, measure, analyse, improve and control. DMAIC approach helps the company to identify the major root cause of any problem. The studies of Markarian [4] state that Six Sigma can not only be used in industrial applications, but it can also be applied to improve business processes such as banks, logistics and supply chain. DMAIC is an effective methodology to solve any problem in any service or manufacturing industry [5]. Several research papers have been published for product or service quality, cost, performance, defect, waste, downtimes, customer satisfaction in achieving operational excellent [6]. The basic tools of DMAIC methodology such as statistical process control (SPC), cause-and-effect analysis, Pareto chart, and design of experiments have been used to implement Six Sigma $[7,8]$.

The study will examine the practical application of DMAIC model in Spices manufacturing company situated in Abuja City of Nigeria. Consolidated Foods Nigeria Limited in Abuja has been known for the manufacturing and packaging spices cubes called Maggi for the past two decades. Consolidated Foods Limited are medium-sized company who requested to implement Lean Six sigma due to their drastically loss of market size as a result of high production of low quality packaged spices products. In the past five years, Consolidated Foods have spent much investment in training and purchase of new production lines to replace the obsolete ones but much to the increase in production of defective packed spices. Hence, only DMAIC phase of Six Sigma can be implemented in these spices manufacturing companies to remove the cost causes of these defects and retain or boost their market share. The research paper surveyed and reviewed various papers connected with the application of lean production tools and elaborated the indispensable advantage of using DMAIC phases in the Lean Product Development. The paper is concluded in the final section by recommending the scope for purposing further study in this direction

\section{Literature Review}

In order to achieve a sustainable improvement in product performance and to reap its eventual gains, the right type of tools and methods must be adopted at the right time to meet the needs of the company. The general needs of companies developing or planning to develop a new product can be summarized as follows;

(1) The need for a eliminate defective supplies to market while maintaining the production performance and

(2) The reduction in the resources needed during and through the product developmental stage.

While the traditional product development tools focus on reduction of the product development cycle-time, the LPDT focus on the elimination of all type of wastes in the product developmental stage most especially the non-value added activities (i.e. wastes as a result of time, people, space, machines, money, decisions, information, etc.) and improvement in the quality of the designed products [9]. Some of the LPDT mentioned in the introductory section, which is used as independent variables in this paper were discussed in details with their literature references, thereafter the trends in performance measurement in companies were reviewed.

Just in time product development (JIT-PD):

JIT-PD is a product development system in which the product development workers are provided with the required amount of information, knowledge, or decisions in the required form for each of the tasks in the product developmental stage. This is mainly to eliminate any form of waste by providing the right decisions, at the right place, at the right time. In the traditional product development process, product design related decisions are decided beforehand, that is at the very start of the product development process. In JIT-PD, the product design decisions are not made until the product enters, say the detail design phase, which contains tasks that need enough information, knowledge or decisions as inputs [10, 11]. A proper implementation of the JIT-PD system is capable of impacting on the performance of the entire organization [12] in terms of an improved profits and return on investment since work in progress (WIP) in the design level is reduced, circulation of unnecessary information is eliminated, product quality is improved, design lead times and the product development costs are checked, [13]. In this approach, the holding and storage costs of information are reduced as well as the costs incurred due to lost or misplaced information or decisions.

Value stream mapping in product development (VSM-PD): The VSM-PD is a graphical tool that consists of product development tasks with a clear view of the current flow of the product and the flow of information in the considered production environment. The value stream helps in mapping out the product development process "door to door. In this method, the wastes, inefficiencies, and non-value-added actions/activities in the system can easily be found and eliminated from the system quickly to achieve a "future state," and give an insight into the possible "ideal state" that should serve as a longer-term goal [14]. The tasks in the value stream product development creates and transform the information by allowing a convergence of dispersed, 
segmented, or diverse information to define the final shape of the design [15], which in turn improve the overall performance of the product development process as well as that of the company.

Standardize work method:

The standardized work method is one of the most important lean tools employed in the product development process and this is said to be centered on organizing, developing and releasing of design guidelines (i.e. a "recipe" on how to do something exactly the same every time) as well as developing a sustainable practice both in manufacturing and product development by standardizing the different tasks to aid all continuous improvement activities [16]. A standardized work method is a detailed, documented and visual system by which associates develop and follow a series of predefined process steps to achieve the overall goal of the organization and improve performances [16].

Single minute exchange of die (SMED):

The formal SMED which is regarded as a systematic approach for reducing machine downtime due to changeovers issues in the manufacturing system by identifying, separating, and modifying the internal and external setup elements (time), has the goal of making the internal and external setup times independent, and then organize the reduction of both time, most especially the internal time. However, the focus of the SMED technique is mainly on the internal setup elements, those requiring downtime, since the external set up elements can be performed as a parallel task when the machine is in operation [9]. In product development process, the changeover in the SMED is considered as the switching between projects for a particular task. In this approach, the single minute exchange of die can be considered as a single minute exchange of project (SMEP). The main goal of SMEP is to allow designers to work on multiple projects at a time by switching between projects, by adjusting themselves for the requirements of different projects in minimum time. This is to curb the unnecessary waste of time, resources, personnel, workstation, machinery, and possible loss of information. This is achieved by following a strategic approach that is, by ensuring the processing of the design or project starts only when the designer/engineer is prepared to begin the processing.

The pull system:

The pull system concept is one of the most important techniques in the product development as it ensures all activities during the design phase are in agreement with the end-customer requirements and this is achieved through the deployment of the Voice of the Customer techniques to collect direct feedback from the customers [17]. In this approach, critical requirements of the customers are determined as well as translating their requirements into product design, process design, and functional engineering. The techniques also ensure that the critical requirements are transferred consistently between the different main-line stations. The much talked about Boeing 777 aircraft is an example of how to pull systems can help in transforming designs into a much more better product.

Value engineering:
This is an evaluative technique used in enhancing the value of the developed product by increasing its functional capability. The goal of the value engineering technique is to eliminate unnecessary features and functions in the product by optimizing the value to cost ratio, which in turn, improves the performance of the product and that of the design company [18].

\section{Marketing research:}

This can be referred to as a systematic way of gathering, recording, and analyzing market data about issues relating to the marketing of a product and services. The goal here is to identify and assess how changing elements of the marketing mix can impact customer behavior about the product [18]. The information gathered using the market research method is then inputted into the new product design (redesign). According to [19], market research activities play a significant and positive role in the overall company's performance.

\section{DMAIC improvement tool:}

This is a distinctive product development six sigma approach to product and quality improvement [20]. The model involves five interconnected stages i.e. Define, Measure, Analyze, Improve and Control (DMAIC). The application of DMAIC phases to implement Lean concept is used to reduce the amount of warp that occurred in a company by name Wilson Tools during heat treatment of punches [21]. During the Define phase, 'Pareto analysis' was conducted to identify the problem occurred in the Wilson tools. One of the problems identified was the warpage occurred in punches during heat treatment. Hence, the objective was set to reduce this warpage. During measure phase, 'Process capability analysis' was used to identify whether the process was capable or not. During analyse phase, warp of the process was measured by choosing 100 punches and measuring the same. Mean and Standard deviation of warp were identified. Subsequently, 'cause and effect diagram' was used to narrow down the scope of the project to improve the heat treatment process. During the improve phase, process map and cause and effect diagram were used to identify the action that will lead to the development of the warpage of punches during the heat treatment process. One of the findings of this Improve phase is that, hanging the punches in the fixture resulted in least amount of warp and variations. In order to control the process, the use of histogram and control charts are recommended for the usage. Finally, it is stated that, implementation of DMAIC phases has resulted in the improvement of process and saving of a considerable amount of money.

\section{Methodology}

The DMAIC methodology was employed to improve the production line performance of Omori line 1 while Six Sigma value level was used to explore hidden opportunities for higher production line performance. The empirical study reported here was carried out in a Spices (Maggi) manufacturing company by name Consolidated Foods Limited situated in Abuja city, Nigeria. In Consolidated 
Foods Limited (CFL), several types of spices like Nutmeg, Curry powder, Black pepper, Maggi and Thyme are manufactured. Among them, Maggi and Curry powder are produced in large volumes to meet the high demand of the customers. As mentioned earlier, during the conduct of the implementation study being reported here, the production of Maggi was chosen as the scope for studying the practical implication of DMAIC model.. The various activities are reported in the following five phases as shown in Figure 1.

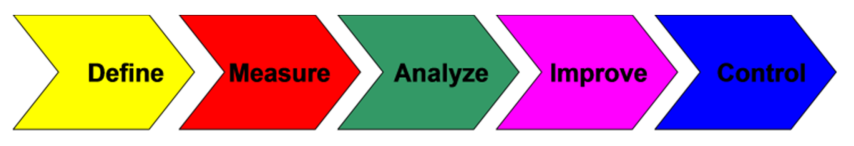

Figure 1. DMAIC Model for Lean Manufacturing.

\subsection{Define Phase}

In the define phase, a Production packaging machine named Omori Line 1 was discovered to have huge potential for overcoming many defects as shown in Figure 2.

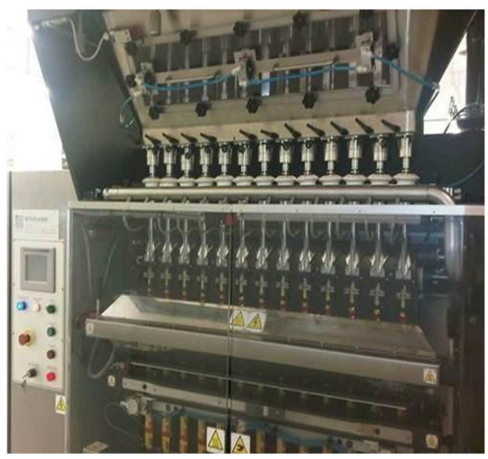

Figure 2. Omori Maggi Processing Line 1.
The raw material from the cyclone passes through the screw conveyor to the suction line by electro-pneumatic automated processes. The product is then delivered to the descending hopper through a magnetic trap. It undergoes the consequent processes of mixing, drying and cooling before stripping prior to the Omori filing lines. At this section, there are several defects and wastes normally generated due to several factors ranging from reel issues, minor stoppages from photo-ye issues, jaw problem in the knife, printing issues due to wrong setting of parameters etc. The Omori Line 1 produces $60 \%$ of production outputs and generated over $75 \%$ of defects simultaneously. Hence, the empirical study is limited to only Omori Line 1 for this reason.

After critical examination of the pilot line (Omori line 1), the first step is to define the Voice of the customer which spelled out the scope of the lean project, using the Is or Is not Template as shown in Figure 3 below.

\begin{tabular}{|c|c|c|}
\hline Action & IS & IS NOT \\
\hline What/Which & $\begin{array}{l}\text { Improve the Line Performance of } \\
\text { Omori Line } 11\end{array}$ & $\begin{array}{l}\text { Optimization of Speed of } \\
\text { Volpack machine }\end{array}$ \\
\hline Where & Filling and Packing room & Pressing and wrapping room \\
\hline When & $\begin{array}{l}\text { From January } 2019 \text { to September } \\
2019\end{array}$ & After 2019 \\
\hline Who & $\begin{array}{l}\text { Quality Manager, Maintenance } \\
\text { Manager, Omori Technician, In-Line } \\
\text { Monitoring Technician, Industrial } \\
\text { Engineer and Mixer operator }\end{array}$ & eacking Line Operator. \\
\hline $\begin{array}{l}\text { How Mu } \\
\text { How Many }\end{array}$ & NGN 12million would be saved per y & year \\
\hline
\end{tabular}

Figure 3. Defining voice of customer using Is/Is not Product Development Tool.

The Project charter was drawn after voice of the customer has been well identified. This is a document stating the purpose of the project. It serves as an informal contract that helps the team stay on track with the goals of the enterprise [21]. Each project charter used in the study consists of the following points:

I. Purpose: Establish goals and objectives

II. Benefits: States how the company will fare better when the project reaches its goal

III. Scope: Provide project limits in terms of budget, time, and other resources
IV.Results: Defines the criteria and metrics for project success.

The project charter for this study was described in details as shown in Figure 4 below. The project goal is to improve the Omori Line 1 performance from $60 \%$ to $76 \%$ through reduction in production cost with quality defined from customer's perspective. The cost benefits of the study is to realize NGR 12 Million per year. The scope of the project is limited to Omori Line 1 for Maggi (Spice) manufacturing. The expected results are improved production \& maintenance operations, elimination of stoppages and increased staff 
morale via training.

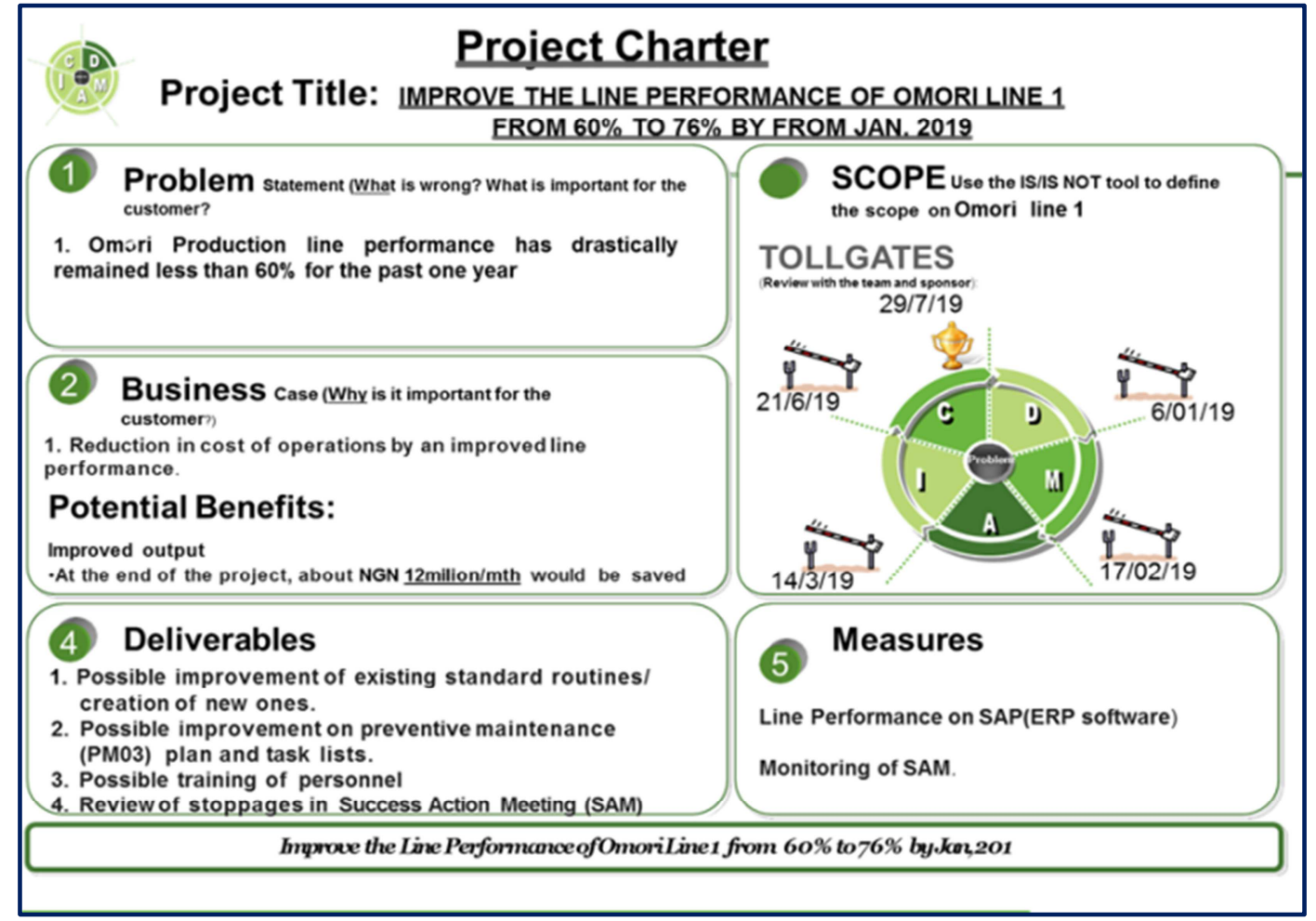

Figure 4. Project Charter Lean Product Development tool for Omori Line 1.

The final sub-section of the Define phase is the project tracking. The succession of all the activities involved in each of the five phases of DMAIC were monitored with a Gantt chart as displayed in Figure 5 below.

\begin{tabular}{|c|c|c|c|c|c|c|c|c|c|c|c|c|c|}
\hline & D. & & & & TIME & & & & & & & & \\
\hline 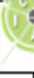 & ACTIVITIES & $\begin{array}{l}\text { PLANNED } \\
\text { VRS REAL } \\
\text { TIME } \\
\end{array}$ & WK 1 & WK 2 & WK 3 & WK 4 & WK 5 & WK 6 & WK 7 & WK 7 & WK 8 & WK 9 & WK 10 \\
\hline & PROBLEM STATEMENT & Planned & & & & & & & & & & & \\
\hline & & & & & & & & & & & & & \\
\hline 啰 & TARGET DEFINITION & Reaned & & & & & & & & & & & \\
\hline & & Planned & & & & & & & & & & & \\
\hline & TEAM CHARTER & Real & & & & & & & & & & & \\
\hline & PROJECT TIMELINE & Planned & & & & & & & & & & & \\
\hline & 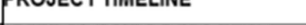 & Real & & & & & & & & & & & \\
\hline & COLLECTION OF BASE LINE & Planned & & & & & & & & & & & \\
\hline & 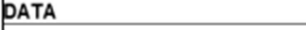 & Real & & & & & & & & & & & \\
\hline 登 & PLOT DATA OVER TIME & Planned & & & & & & & & & & & \\
\hline क & & Real & & & & & & $\begin{array}{l}\text { Istoposper } \\
\text { Imucker }\end{array}$ & & & & & \\
\hline 贫 & STRATIFY PROBLEM & Planned & & & & & & plant & & & & & \\
\hline & & Real & & & & & & Holday & & & & & \\
\hline & MAP PROCESS (FLOW CHART) & Real & & & & & & & & & & & \\
\hline & BRAINSTORM & Planned & & & & & & & & & & & \\
\hline & 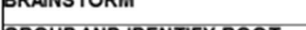 & Real & & & & & & & & & & & \\
\hline z & GROUP AND IDENTIFY ROOT & Planned & & & & & & & & & & & \\
\hline & CAUSES & Real & & & & & & & & & & & \\
\hline న & CONFIRM ROOT CAUSES WITH & Planned & & & & & & & & & Line ide and & & \\
\hline & DATA & Real & & & & & & & & & delay in supply & & \\
\hline & STRATIFY ROOTCAUSES & Planned & & & & & & & & & & & \\
\hline & 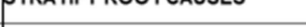 & Real & & & & & & & & & & & \\
\hline & IDENTIFY SOLUTIONS & Planned & & & & & & & & & & & \\
\hline $\bar{\Sigma}$ & 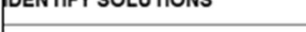 & Real & & & & & & & & & & & \\
\hline & PRIORITISE SOLUTIONS & Planned & & & & & & & & & & & \\
\hline oิ & " & Real & & & & & & & & & & & \\
\hline & CONFIRM ATTAINMENT OF & Planned & & & & & & & & & & & \\
\hline & PROJECT GOALS WITH DATA & Real & & & & & & & & & & & \\
\hline & MONITORPROGRESS & Planned & & & & & & & & & & & \\
\hline & 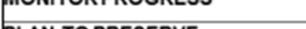 & Real & & & & & & & & & & & \\
\hline 8 & PLAN TOPRESERVE & Planned & & & & & & & & & & & \\
\hline$\underline{z}$ & MPROVEMENT & Real & & & & & & & & & & & \\
\hline & KNOLEDGE SHARING WITH & Planned & & & & & & & & & & & \\
\hline & STAKE HOLDERS & Real & & & & & & & & & & & \\
\hline & SHARE SUCCESS STORY & Planned & & & & & & & & & & & \\
\hline & 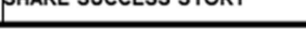 & Real & & & & & & & & & & & \\
\hline
\end{tabular}

Figure 5. Omori line 1 Project Tracking using Gantt chart. 


\subsection{Measure}

At the implementation phase, a plan for collection of data was agreed by project team members who were crossfunctional employees from production, maintenance, logistics, quality, finance and sales departments. The Table 1 below shows the details of the data. The measurement system used for data collections were collected using situation videos and from SAP (Company enterprise resource planning software).

Table 1. Data Collection Plan for Omori Line 1 Performance Measurement.

\begin{tabular}{llllll}
\hline $\begin{array}{l}\text { What to Measure } \\
\text { (WHAT) }\end{array}$ & $\begin{array}{l}\text { Measuring } \\
\text { Unit }\end{array}$ & $\begin{array}{l}\text { Sample } \\
\text { (WHEN) }\end{array}$ & $\begin{array}{l}\text { How to collect } \\
\text { (HOW) }\end{array}$ & Why this data is needed (WHY) & $\begin{array}{l}\text { Person in charge } \\
\text { (WHO) }\end{array}$ \\
\hline Stoppages & Hours & $\begin{array}{l}\text { January 2019 to } \\
\text { September 2019 }\end{array}$ & $\begin{array}{l}\text { Collation of stoppages } \\
\text { over the set period }\end{array}$ & $\begin{array}{l}\text { To determine the extent to which the } \\
\text { stoppages affects the line performance }\end{array}$ & $\begin{array}{l}\text { Gbededo and } \\
\text { Sefiu }\end{array}$ \\
\hline
\end{tabular}

The processes involved in Maggi spice production were determined using the Flowchart. A key step in understanding processes was the use of the flowchart as shown in Figure 6 below. This flowchart created a situation for broader perspective for potential problems and opportunity for product improvement. The critical area of constant bottleneck were identified by a broken red oval shape as shown in Figure 6 below.

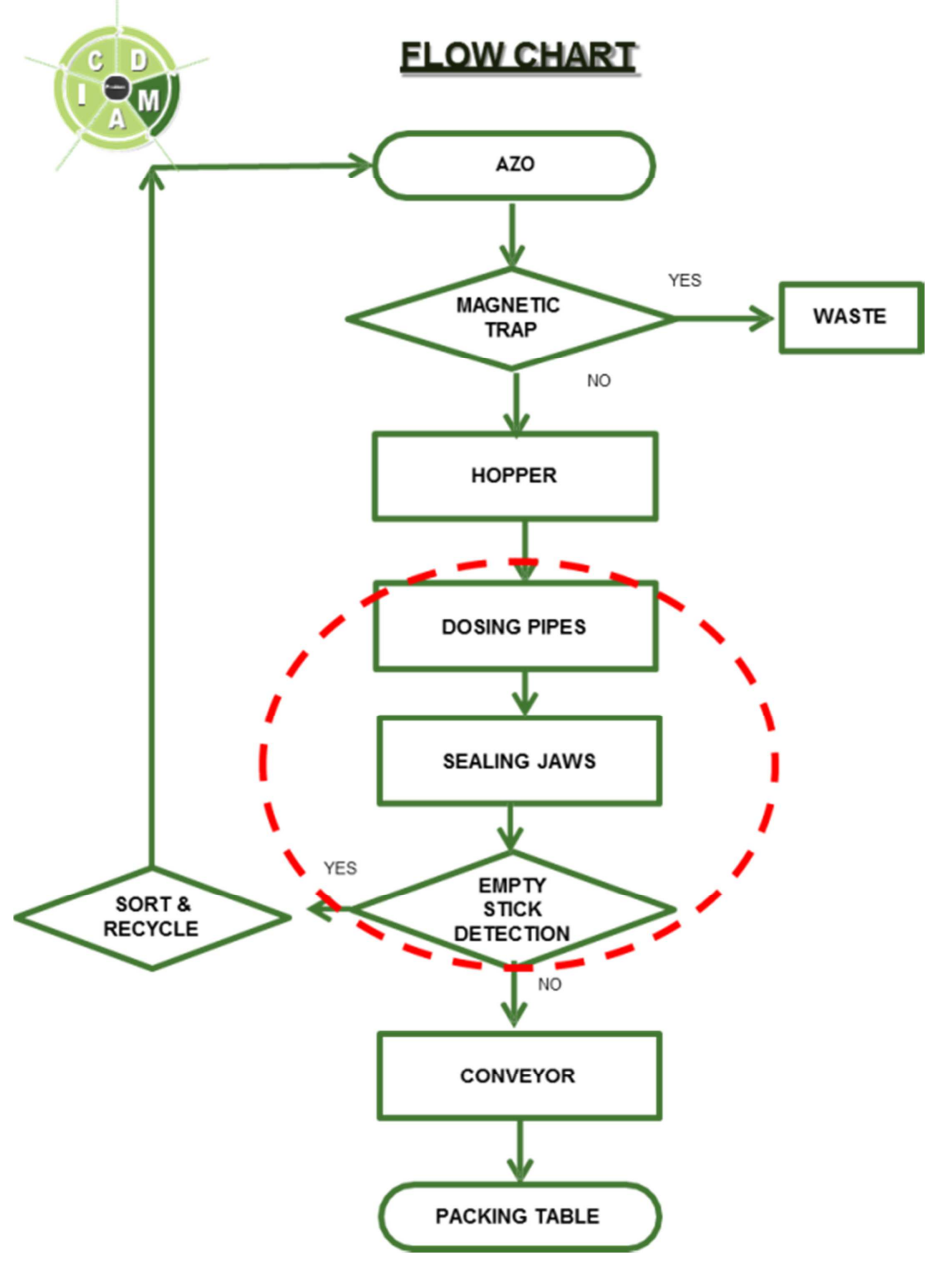

Figure 6. Flowchart for Maggi spice manufacturing at Omori Line 1.

A sample of 30,000 Maggi spice cubes were collected at random around the dosing pipes, sealing jaws and empty stick detector areas. Each group 20 spice cubes were inspected for defects using Optical coherence tomography (OCT). It was used in this study to detect surface texture and sub-surface powder, which was unmelted or insufficiently sintered, known to be a common cause of poor product quality. Each spice cube unit was inspected for surface roughness and squareness. The cubes were examined per score until the last sample was inspected. Data for defective samples were recorded as shown tin Table 2 below. 
Table 2. Statistics of defects reported in the manufacturing of Maggi cubes on Omori Line 1.

\begin{tabular}{lllll}
\hline & Name of Defect & $\begin{array}{l}\text { Number of Defects in a sample of } \\
\mathbf{1 7 0 0 0} \text { Maggi cubes }\end{array}$ & $\begin{array}{l}\text { \% of Defects in Sample of } \\
\mathbf{1 7 0 0 0} \text { Maggi cubes }\end{array}$ & $\begin{array}{l}\text { Cumulative \% of Defects in Sample } \\
\text { of 15000 Maggi cubes }\end{array}$ \\
\hline 1 & Reel issues & 9800 & 58 & 56 \\
2 & Doser blockage & 4000 & 24 & 82 \\
3 & Plan stoppages & 1200 & 7 & 89 \\
4 & Inkjet faults & 1000 & 6 & 95 \\
5 & Knife problems & 600 & 3 & 98 \\
6 & Others & 400 & 2 & 100 \\
& Total & 17000 & & \\
\hline
\end{tabular}

As shown in Table 2, out of 30,000 Maggi cubes inspected, 17,000 of them have been rejected. Based on the observations made from this data, the sigma value was determined. The procedure used to determine the Sigma level is presented below:

Defects per unit $($ DPU $)=$ Total number of defective cubes rejected $\div$ Total number of cubes inspected

$$
\begin{aligned}
& =17000 \div 30000 \\
& =0.566
\end{aligned}
$$

Since six defects were considered, the number of opportunities $(\mathrm{O})$ that cause the production of defective Maggi cubes is six. Therefore,

$$
\text { Defects per opportunity }(\mathrm{DPO})=\mathrm{DPU} \div \mathrm{O}
$$

where $\mathrm{O}$ refers to the number of opportunities.

$$
\begin{aligned}
& =0.566 \div 6 \\
\text { DPO } & =0.0944
\end{aligned}
$$

Now,

Defects per million opportunities $(\mathrm{DPMO})=\mathrm{DPO} \times$ $1,000,000$

$=0.0944 \times 1,000,000$

$=94400$
From the Six Sigma conversion table (Appendix 28, Certified Six Sigma Black Belt Handbook, 2008), it was found that Sigma value against 94,400 DPMO in the case of manufacturing of Maggi Spice cubes in this study reported here was 2.80 .

Hence, this value is quiet less than 6 Sigma, it was inferred that opportunities exist to improve the Sigma level by overcoming defects in manufacturing of Maggi spice cubes along Omori Line 1 st Consolidated Foods Limited. In line to this observation, as mentioned earlier, in the study being reported here, efforts were made to overcome reel issues in the production of Maggi spice cubes on Omori Line 1.

The Pareto chart was drawn for all the six types of defects according to the data obtained in Table 2. The chart is based on "Pareto Principle" which states that, for many events, roughly $80 \%$ of the effects come from $20 \%$ of the causes [22]. The real goal of any Six Sigma project is to find the top two or three factors that make up the true Pareto chart for a given problem, and then control those factors to achieve breakthrough performance. The Figure 7 below shows that there is relationship between product performance and DMAIC, lean product performance model since only two factors accounted for $80 \%$ of the problem at Omori Line 1. In this case, there was low performance of the Omori Line 1 as a result of large production of defective Maggi cubes.

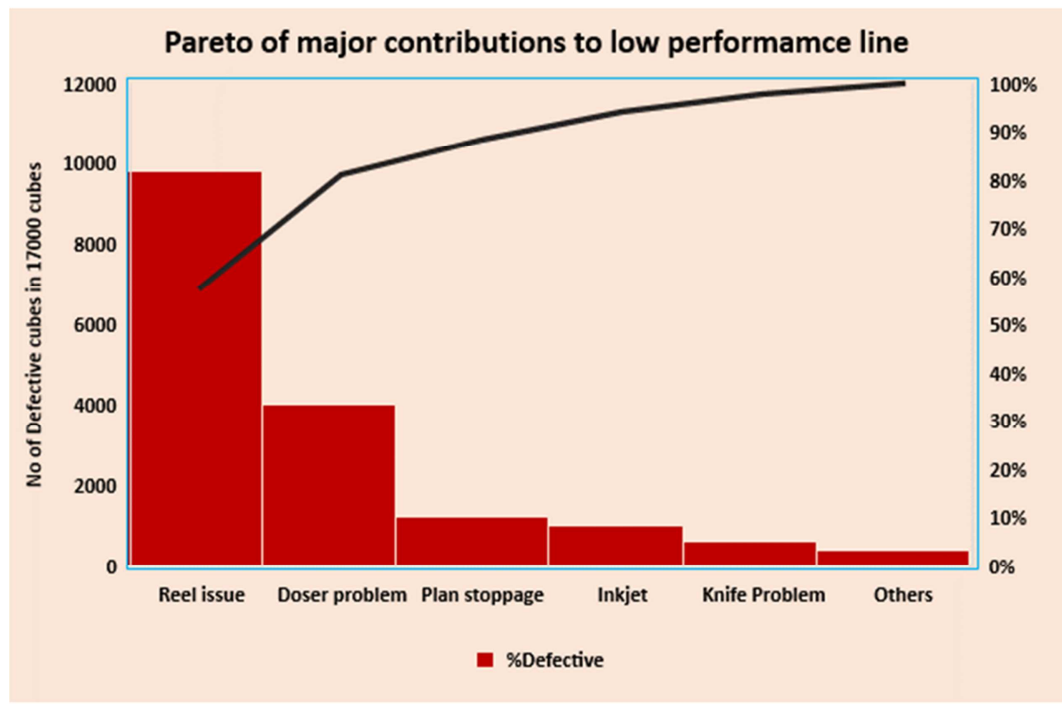

Figure 7. Major contributions to low performance on the Omori Line 1. 
Further investigation were carried using situational videos camera and comparing it with data from SAP to ensure uniformity of data, for all the factors relating to the reel issue causing defective spice cubes. The data shown in Table 3 is a summary of the data collected as a result of factors related to reel issues on Omori Line 1.

Table 3. Statistics of stratified defects from Reel Issues on Omori Line 1.

\begin{tabular}{llll}
\hline Reel Issue Defect & Number of defects per Reel Issues & \% defects Per Reel Issues & Cumulative \% Per reel Issue \\
\hline Off-setting & 5100 & 52 & 52 \\
Packing material & 2800 & 29 & 81 \\
Edge trimmer & 1000 & 10 & 91 \\
Reel change & 500 & 5 & 96 \\
Mark detection & 400 & 4 & 100 \\
\hline
\end{tabular}

From the data obtained in Table 3, the Pareto chart in Figure 8 was drawn for all the issues related to defects as a result of reel issues on the Omori line 1.

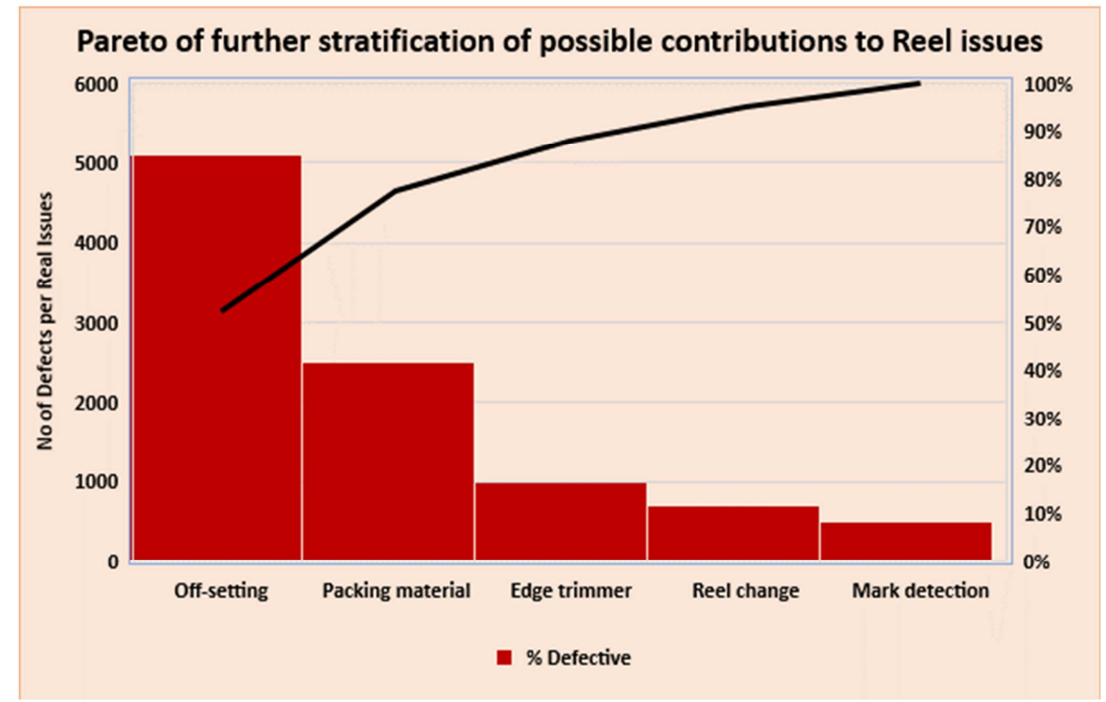

Figure 8. Pareto chart for all Defects related to Reel Issues on Omori Line 1.

\subsection{Analyse}

In the analyse phase of the DMAIC model, brainstorming sessions were held by Top management and shop floor teams to evaluate all the factors that could led to any off-setting failures on the reel. During this kaizen session, a total number of fourteen problems were recommended by the Six Sigma teams as possible causes of offsetting defects in the reel. The report of evaluation of the kaizen (Japanese word for continuous improvement) session were documented and presented in Figure 9 below.

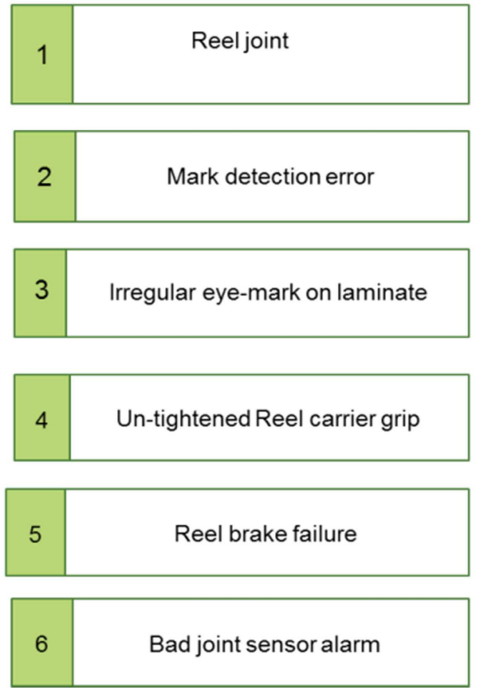

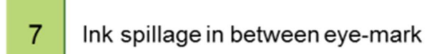
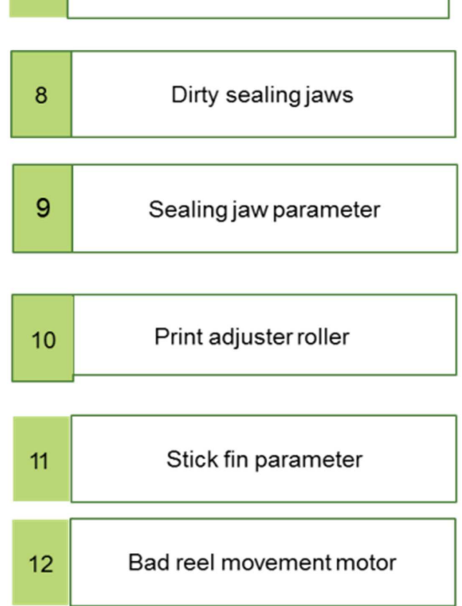
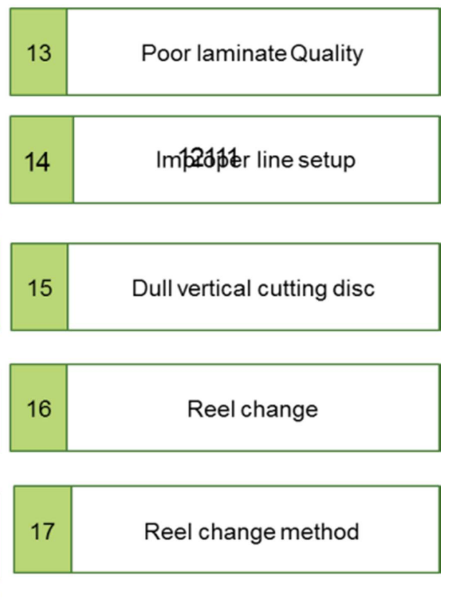

Figure 9. Brainstorming activity on low performance with respects to Reel offsetting on Omori Line 1. 
The brainstormed root causes were presented in the causeand-effect diagram, shown in Figure 10. In the analysis of diagram, we can assess that the main causes of spices loss were: (i) Mark detection error

(ii) Bad reel joint sensor alarm

(iii) Dull vertical cutting knives

(iv) Inconsistencies in reel joint

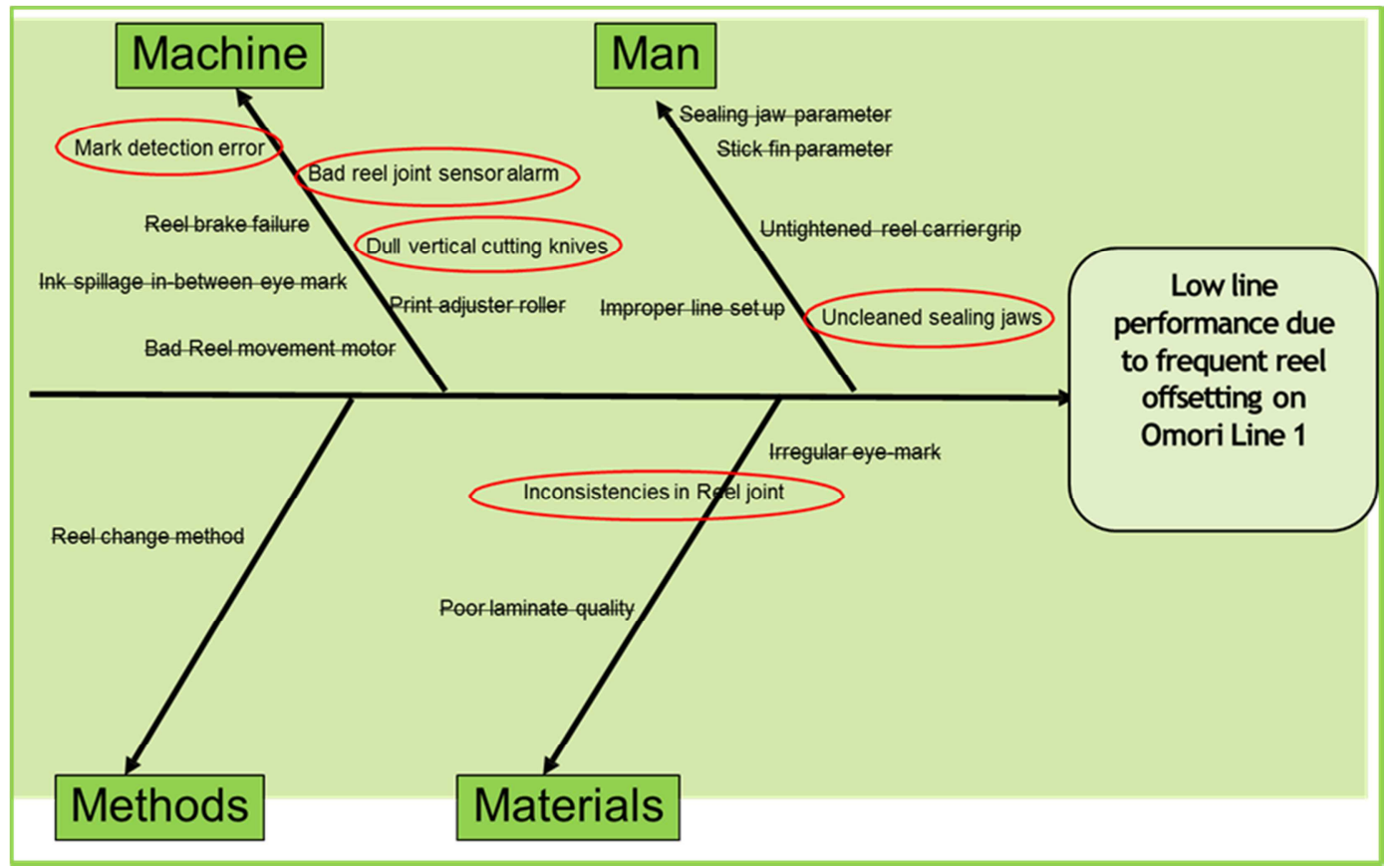

Figure 10. Cause and effect Diagram for Root causes analysis of Reel offsetting problems on Omori line 1.

\subsection{Improve}

In order to reduce reel offsetting losses due to the obtained causes already discussed, several solutions were suggested. These solutions were considered for each root cause. Moreover, the constituted information provided by the improvement team members in Figures 11 and 12 illustrated the obtained root causes, effects of causes and suggested solutions. The impact of each root cause was obtained by analysing the monthly reports of production department for the past 12 months.

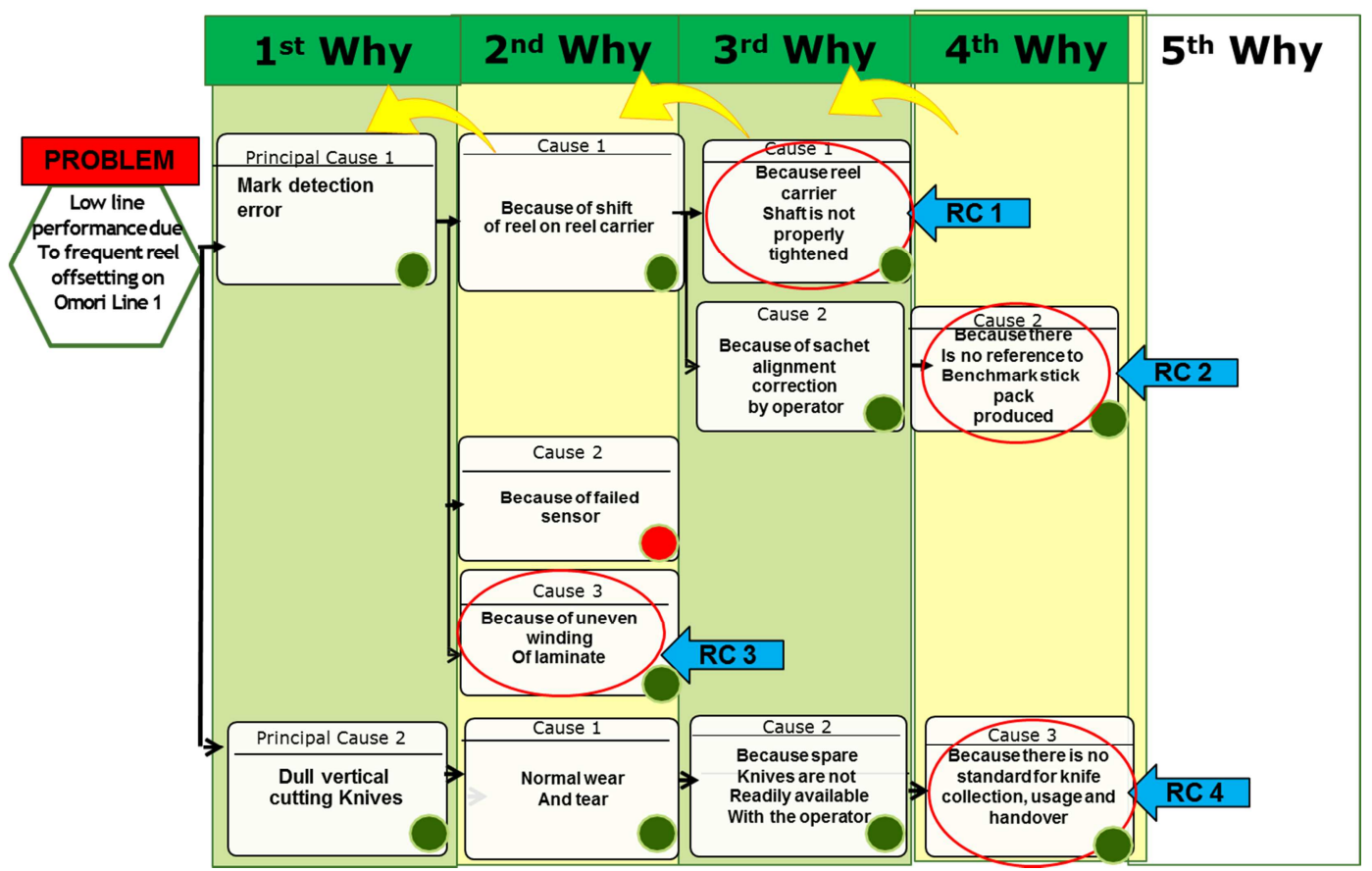

Figure 11. Improvement solutions for each of the root causes of Reel offsetting on Omori Line 1. 


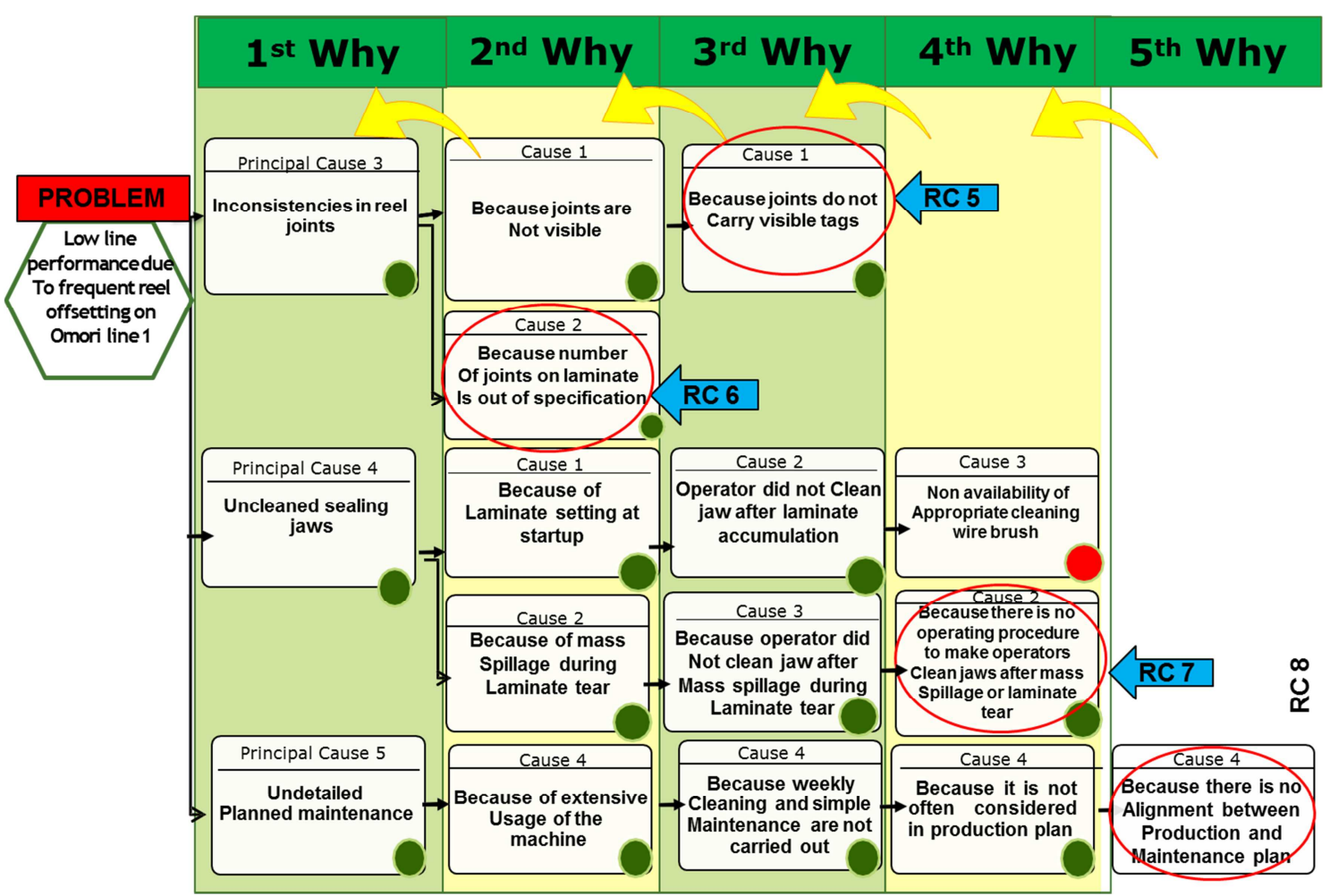

Figure 12. Improvement solutions for each of the root causes of Reel offsetting on Omori Line 1.

The results of evaluation obtained shows that the Line performance of Omori Line 1 improved from $60 \%$ to $76 \%$ from the month of April 2019 after the removal of product defects through the implementation of DMAIC model as shown in Figure 13.
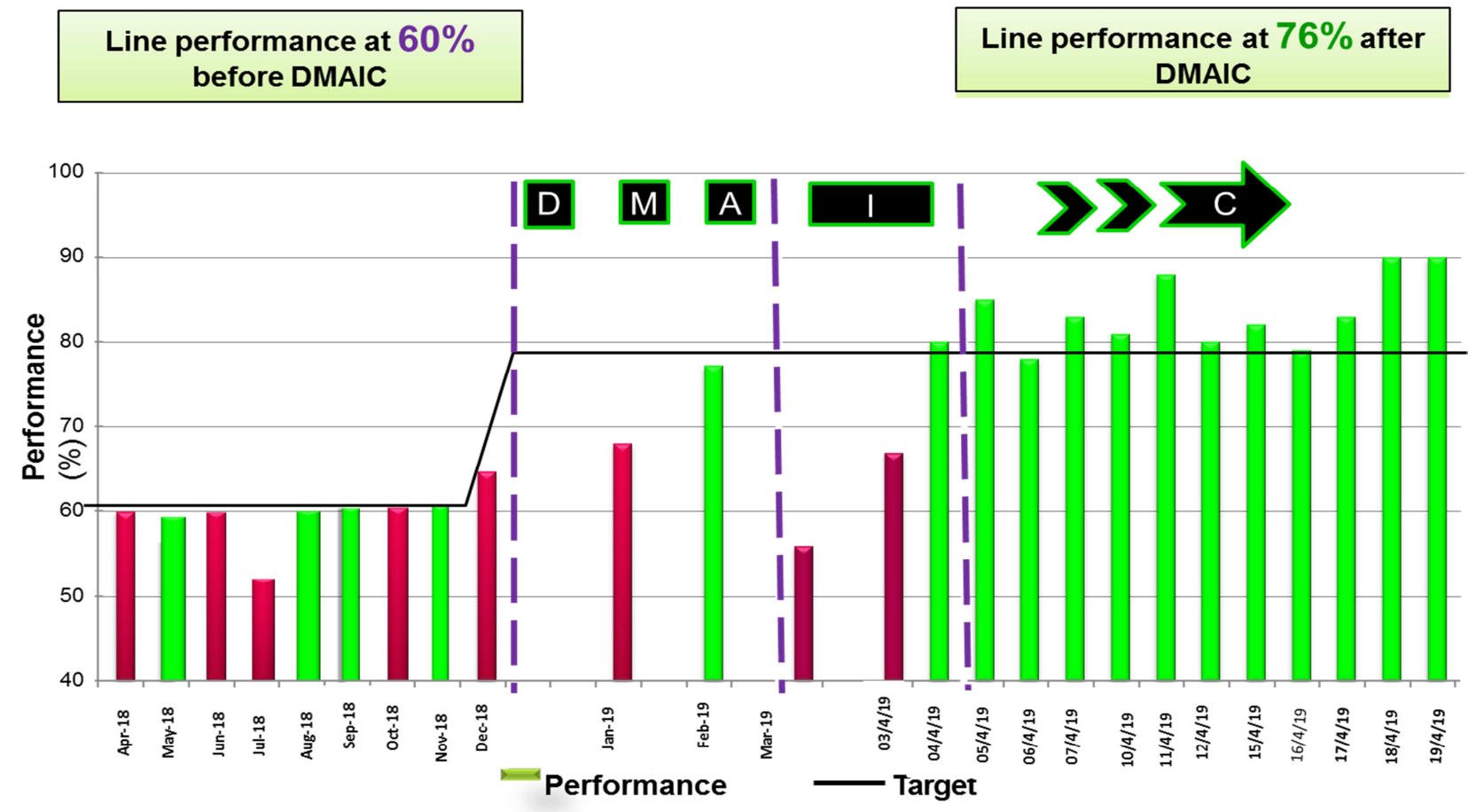

Figure 13. Omori Line 1 performance before and After DMAIC project.

\subsection{Control}

This is the last phase of the Lean Production Development Tools (LPDT) for Line performance using, DMAIC model.
The real strength of the DMAIC steps is the control step. The cost savings after the removal of product defects in the improve phase is shown in Figure 14 below in the September financial statement of the company. 


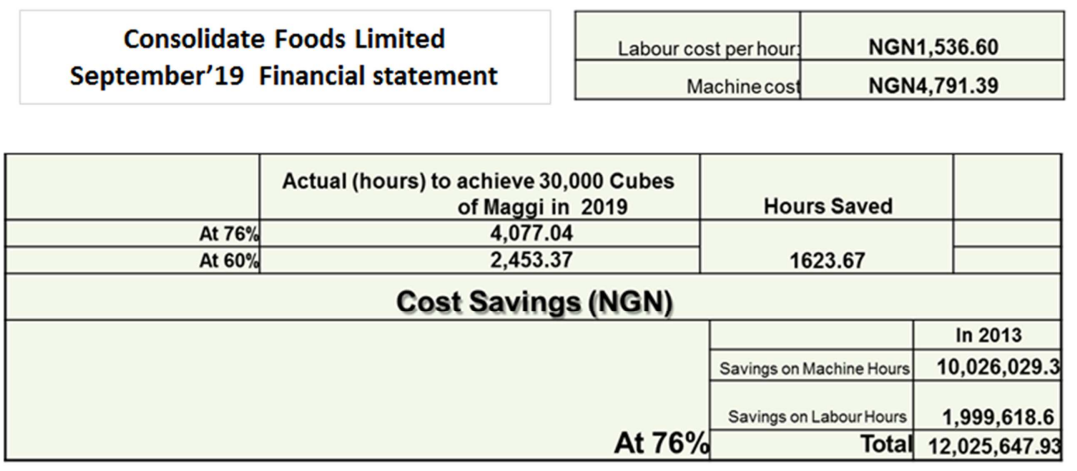

Figure 14. Financial cost savings statement form Consolidated Foods Limited after DMAIC project.

During this phase, the goal of the 'control' phase is to maintain the financial gains from the suggested solutions and prevent the re-occurrence of product defects. Nevertheless, due to time limitation, this phase is still under improvement at the Omori Line 1 in Consolidated Foods Limited (CFL) which was investigated in this paper. In order to get long-lasting effects, periodical observation of the process is required to detect the changes and keep it under control. The control phase ensured, successful implementation of the team's recommendations for keeping long-term success sustained. The new and improved process were outlined using One Point Lesson (OPL) as the new standard operation procedures. Results will continue to be tracked so that any "drift" back to previous results can be monitored and addressed in a proactive manner. The use of checklists and Kaizen boards for periodic updates of shop floor teams also go a long way in keeping the results intact.

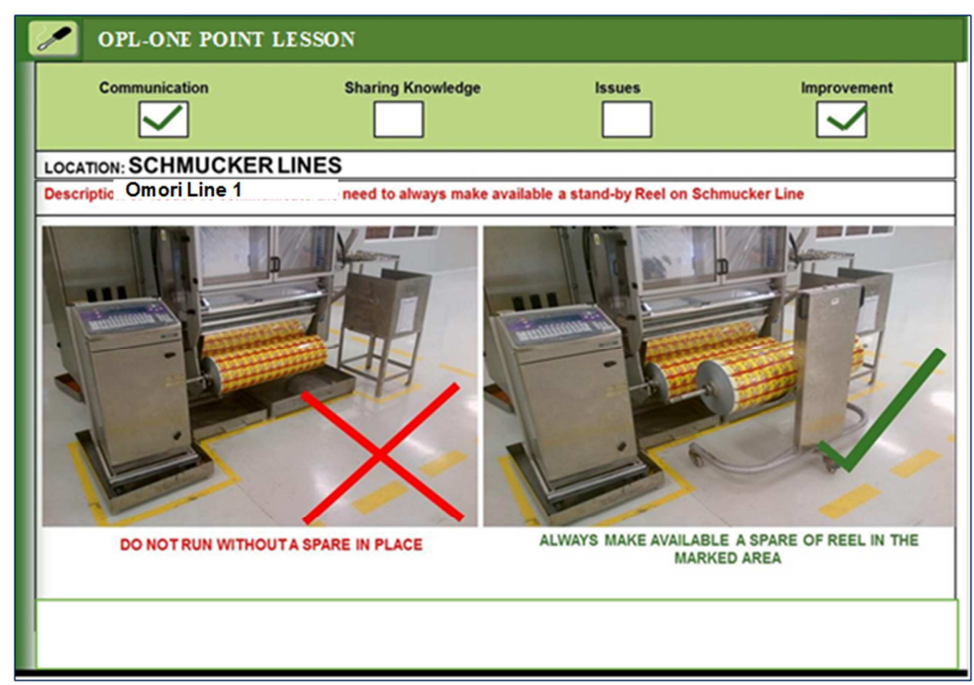

Figure 15. Control measures on Omori Line 1 Using OPL.

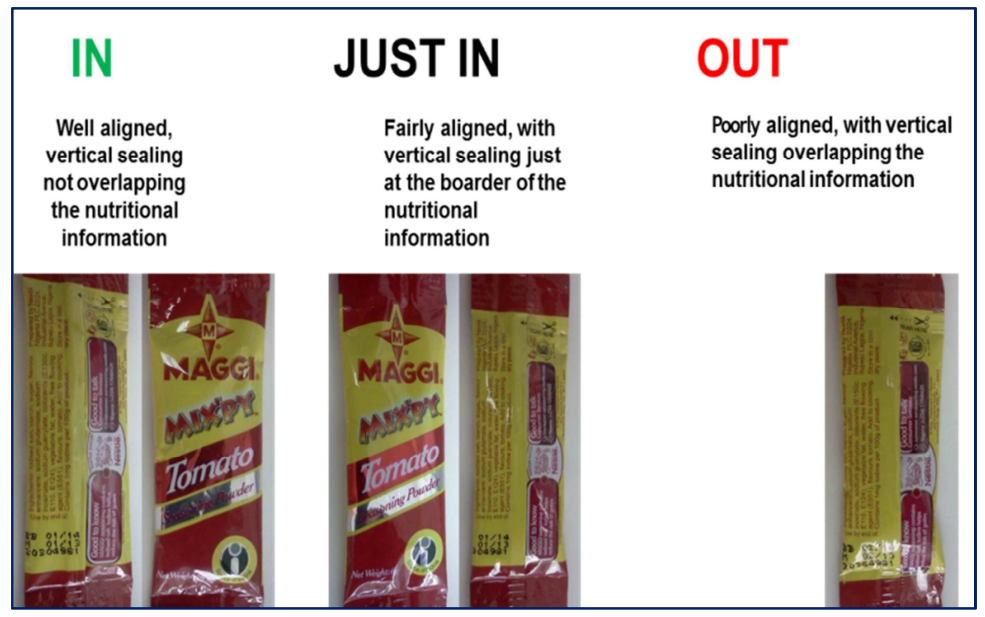

Figure 16. Standard for Strand Alignment on Omori Line 1. 


\section{Conclusion}

This paper examined the relationship between product performance and lean product development tools using DMAIC model. DMAIC Six Sigma methodology, was used to find root causes of high rate of defective Maggi cubes on the Omori Line 1 and proffer solutions to eliminate these defects in order to improve line performance from $60 \%$ to $76 \%$ and sustain the results achieved through the improve phase. First, Is/Is not template was used to establish the voice of the customer and project charter was used to define the purpose, goals and cost benefits of the DMAIC model. The method of data collection was planned and actions were carried out according to plan. The collected data were analysed to establish the defects per million opportunities, which resulted to the determination of Six Sigma level. The Six Sigma level signified the areas in need of improvement along the Omori Line 1. At the end of the data analysis, the results of Pareto chart shows that the reel offsetting problems contributed heavily to low performance of the line. Various improvement tools such as cause and effect diagram, 5 Why, were used to streamline the suggestions made at the brainstorming meetings. At the end of lean implementation, the results obtained showed that DMAIC model is an effective tool to show the relationship between product performance and Lean Product Development Tool (LPDT). This result was observed in the data collected for 12 months along Omori Line 1. A total cost saving of NGR 12.03 million was realised after the DMAIC project. The future research direction will be to further examine the relationship of other statistics tools such as X chart, Chi-test to evaluate the relationship of DMAIC methodology with other lean improvement tools such as Total Production maintenance and Value Stream Mapping.

\section{References}

[1] Aikhuele, D. O., \& Turan, F. M. (2016). A Hybrid Fuzzy Model for Lean Product Development Performance Measurement. IOP Conference Series: Materials Science and Engineering, 114 (1), 012048.

[2] Shafer, S. M. and Moeller, S. B. (2012) 'The effects of Six Sigma on corporate performance: an empirical investigation', Journal of Operations Management, Vol. 30, Nos. 7-8, pp. $521-532$.

[3] Black, K. and Revere, L. (2006) 'Six Sigma arises from the ashes of TQM with a twist', International Journal of Health Care Quality Assurance, Vol. 19, Nos. 2-3, pp. 259-266.

[4] Markarian, J. (2004) 'Six Sigma: quality processing through statistical analysis', Plastics, Additives and Compounding, Vol. 6, No. 4, pp. 28-31.

[5] Pan, Z., Ryu, H. and Baik, J. (2007) 'A case study: CRM adoption success factor analysis and Six Sigma DMAIC application', 5th Acis International Conference on Software Engineering Research, Management and Applications, SERA 2007, IEEE, 20-22 August, Busan, South Korea, pp. 828-838.
[6] Deshmukh, S. and Lakhe, R. (2008) 'Six Sigma-an innovative approach for waste reduction: a case study of an Indian SME', IEEE International Conference on Industrial Engineering and Engineering Management, IEEM 2008 IEEE, 8-11 December, Singapore, pp. 1553-1556.

[7] Meng, L., Lu, C., Xi, X. and Zhang, G. (2011) 'Application of Six Sigma method in improving the quality of box parts', International Conference on Electronic and Mechanical Engineering and Information Technology (EMEIT), IEEE, 12-14 August, Harbin, China, pp. 4158-4161.

[8] Gunasekaran, A., Patel, C., \& Tirtiroglu, E. (2001). Performance measures and metrics in a supply chain environment. International Journal of Operations \& Production Management (Vol. 21).

[9] Pavnaskar, S., Gershenson, J. (2005), “A systematic method for leaning engineering processes" Proceedings of the ASMEDesign Engineering Technical Conferences, Long Beach, CA, USA.

[10] Meybodi, M. Z. (1995). The impact of just-in-time practices on new product development: a managerial perspective, $\mathrm{X}$ (X).

[11] Meybodi, M. Z. (2003). Using principles of just-in-time to improve new product development process. Advances in Competitiveness Research (Vol. 3).

[12] Abdallah, A. B., \& Matsui, Y. (2007). The relationship between JIT production and Manufacturing strategy and their impact on JIT performance. In Proceedings of the 18th Annual Conference of Production and Operations Management Society (pp. 1-35).

[13] Hensley, R. L. and Dobie, K. (2005) 'Assessing readiness for Six Sigma in a service setting', Managing Service Quality: An McManus, H. (2005). Product Development Value Stream Mapping (PDVSM) Manual Release 1.0. Massachusetts Institute of Technology, (September).

[14] McManus, H. (2005). Product Development Value Stream Mapping (PDVSM) Manual Release 1.0. Massachusetts Institute of Technology, (September).

[15] Graebsch, M., Seering, W. P., \& Lindemann, U. (2007). Assessing Information Waste in Lean Product Development. Proceedings of the International Conference on Engineering Design (ICED), (August), 1-12.

[16] Krichbaum, B. D. (2008). Standardized Work: The Power of Consistency Standardized Work: The Power of Consistency Standardized Work: The Principles.

[17] Guerra, L., Murino, T., \& Romano, E. (2010). A System Dynamics Model for a Single-stage Multi-product Kanban Production System. Proceedings of the 11th WSEAS International Conference on Automation \&\#38; Information, 171-176.

[18] Wang, L., Ming, X. G., Kong, F. B., Li, D., \& Wang, P. P. (2012). Focus on implementation: a framework for lean product development. Journal of Manufacturing Technology Management, 23, 4-24.

[19] Ayuba, B., \& Kazeem, A. O. (2015). The role of marketing research on the performance of business organizations. European Journal of Business and Management, 7 (6), 148-156. 
[20] Jirasukprasert, P., Garza-Reyes, J. A., Soriano-Meier, H. and Rocha-Lona, L. (2012) 'A case study of defects reduction in a rubber gloves manufacturing process by applying Six Sigma principles and Dmaic problem solving methodology', International Conference on Industrial Engineering and Operations Management, 3-6 July, Istanbul, Turkey, pp. 7781.
[21] Kumar, U. D., Nowicki, D., Ramirez-Marquez, J. E. and Verma, D. (2008) 'On the optimal selection of process alternatives in a Six Sigma implementation', International Journal of Production Economics, Vol. 111, No. 2, pp. 456-467.

[22] V. Pareto Manuale d' Economia Politica, 1909 (1971) (English translation, A. M. Kelly). 